\title{
Use of Bioelectrical Impedance Analysis (BIA) for Predicting Body Fat in Three Populations of Hibernating Black Bears
}

\author{
Authors \\ H. J. Harlow, D. B. Tinker, J. R. Erwin, R. G. Grogan, T. D.I. Beck, and J. Kiel
}




\title{
USE OF BIOELECTRICAL IMPEDANCE ANALYSIS (BIA) FOR PREDICTING BODY FAT IN Three Populations of Hibernating Black BeARS
}

\author{
H.J. HARLOW $\downarrow$ D.B. TINKER $\downarrow$ J.R. ERWIN $\downarrow$ R.G. GROGAN \\ UNIVERSITY OF WYOMING $\downarrow$ LARAMIE \\ T.D.I. BECK $\downarrow$ COLORADO DIVISION OF WILDLIFE \\ J. KIEL $\downarrow$ PHILLIPPS UNIVERSITAT
}

\begin{abstract}
$\uparrow \quad$ ABSTRACT
Bioelectrical impedance analysis (BIA) is a tool used to provide a measure of body water content and total body fat in an organism. Recently, researchers have validated BIA against tritiated water techniques in the laboratory and proposed it as a fast, non-invasive method for assessing body condition in free-ranging black bears. In the present study, we field tested BIA as a plausible tool for investigating body fat utilization during hibernation by three black bear populations in the Rocky Mountains. Body fat content in the fall ranged from a mean of about $39 \%$ for a group of large, lactating females down to about $29 \%$ by two groups of bears consisting of males and mostly non-lactating females. Daily rates of body fat use were greater for the larger, lactating female group than either of the other two groups. Although the fat data determined by BIA appear useful in terms of trends and relative changes, many of the absolute values are inconsistent and perhaps inaccurate. Because BIA is so sensitive to a variety of factors typical of field conditions, we recommend it not be used as the sole source for assessing body condition of large animals such as black bears.
\end{abstract}

\section{$\downarrow \quad$ INTRODUCTION}

Black bears (Ursus americanus) exhibit a profoundly unique overwintering strategy. These animals remain in a mild state of hypothermia without violent shivering or thermogenesis associated with periodic arousal typical of small mammal hibernators (Nelson, 1973). Protein is a major energy substrate utilized by small mammals during arousal from hibernation, however, bears may conserve lean tissue by avoiding gluconeogenic shivering and rely more heavily upon fat reserves. Additionally, female black bears give birth to cubs during midwinter and may require greater fat stores to provide energy for cub development.

Although the body composition of bears, specifically the percent of body lipid, has been determined on captive bears fed artificial diets, we have little information about the composition and utilization of fat stores in the free-ranging, hibernating bear. Certainly, the reported RQ values and triglyceride concentrations in plasma of captive bears tell us that fat is the primary substrate of energy production (Nelson, 1973). However, it is not known how much fat is accumulated for hibernation and if additional fat is required by lactating bears under natural conditions. The knowledge of fat requirements as a nutrient to lactating and non-lactating female as well as male 
bears is important for understanding winter survival of these animals and to formulate management decisions based upon spring emergence conditions.

Traditionally, bear biologists have depended upon measurements of morphometry, visual scores, and blood indices to assess the body condition of bears in the wild (Hellgren et al, 1989, 1993; Cattet, 1990). But, these indicators have not been validated and often prove inaccurate or imprecise. Recently, bioelectrical impedance analysis (BIA) has been used as a rapid, noninvasive method effective for determining body composition of captive bears (Farley and Robbins, 1994). While this method was credited to estimate body fat on captive bears with a high degree of certainty ( $r=$ .993), no studies have reported its reliable use on field populations of free ranging bears under inclement climatic and difficult topographic conditions. The purpose of this study was to: 1) field test the BIA technique to determine if consistent and realistic values of body fat could be obtained 2) use the BIA method to determine the extent of fat utilization by overwintering bears and 3) test the hypothesis that lactating female bears have higher fat demands than non-lactating female and male bears.

\section{$\downarrow \quad$ METHODS}

BIA measures the resistance and reactance of a weak electrical current passed through the body. The empiric nature of the relation between resistance and reactance measured by BIA and body composition has led Farley and Robbins (1994) to the development of equations that translate the raw data from captive black bears into liters of body water, kilograms of fat-free mass and fat mass. These equations were employed in the present field study to estimate body condition of hibernating black bears. In a preliminary visit with Farley and Robbins, we were instructed on the proper placement of leads and use of the BIA in order to insure consistency between their laboratory and this field assessment of body fat of bears.

Body fat was measured on 3 groups of bears from 3 localities with differing vegetation and topographic conditions. Six lactating female bears with an average body mass of $106 \mathrm{~kg}$ were monitored starting in early November from the Uncompahgre Plateau in west central Colorado. Eight adult female bears (2 lactating) with an average body mass of $64.7 \mathrm{~kg}$ were monitored in Middle Park in north-central Colorado starting the last weekend in November. Four females and one male with an average body mass of $61.9 \mathrm{~kg}$ were monitored in the Snowy Range mountains from southeastern Wyoming starting in mid February. Extrapolated body mass back to fall values for the Snowy Range bears was $74 \mathrm{~kg}$.

Bears were anesthetized using Telazol (1 $\mathrm{ml} / 100 \mathrm{Kg}$ ) or Ketamine Hydrochloride/Xylazine Hydrochloride $(200 \mathrm{mg}$ Ketamine and $50 \mathrm{mg}$ Xylazine $\mathrm{mL}^{-1}$ ) administered with either a jab-stick or dart gun while in the den. The bears were removed from the den, weighed using a digital load scale (200 gm accuracy), and were placed upon a Therma-Rest pad and plastic tarp for appropriate positioning in preparation for BIA as directed by Farley and Robbins (1994). The BIA instrument consists of a hand-held RJL Systems model 101-Q impedance meter and two pairs of dual electrical leads quipped with alligator clips. One set of leads was attached to either side of the upper lip behind the canines while the second set was attached to 1 ", 20 -gauge vacutainer needles inserted into the fat deposits $2 \mathrm{~cm}$ on either side of the base of the tail. The greatest care was taken to maintain consistency of bear positioning and lead placement, and all measurements of resistance and reactance were taken twice to insure precision. Resistance values along with measurements of snout-tail length and body mass were used to calculate total body water and total body fat from formulas presented by Farley and Robbins (1994). Statistical analysis was conducted using a paired $t$-test of values from bears measured in early and late winter.

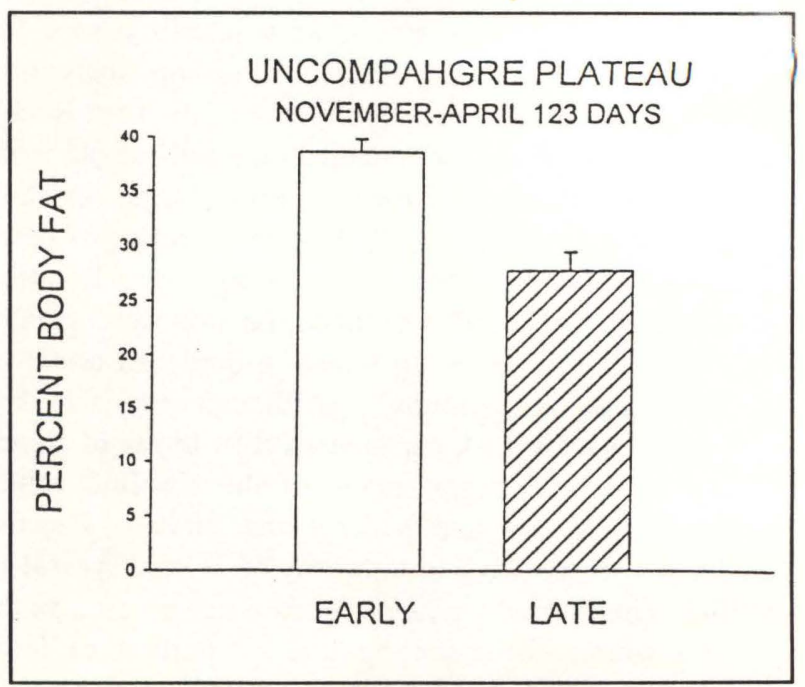

Figure 1. Percent body fat of black bears during early and late winter in the Uncompahgre Plateau, Colorado. Vertical lines represent 2 SEM. 


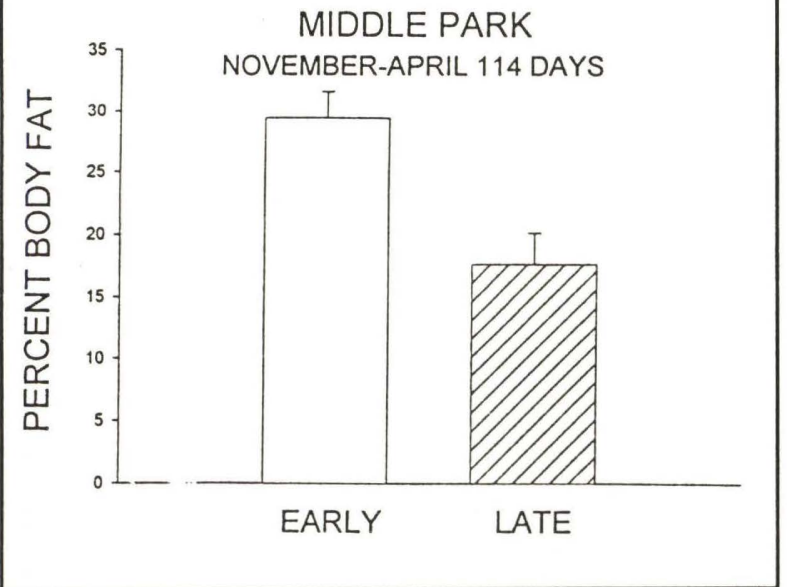

Figure 2. Percent body fat of 8 female black bears during early and late winter in Middle Park, Colorado. Vertcal lines represent 2 SEM.

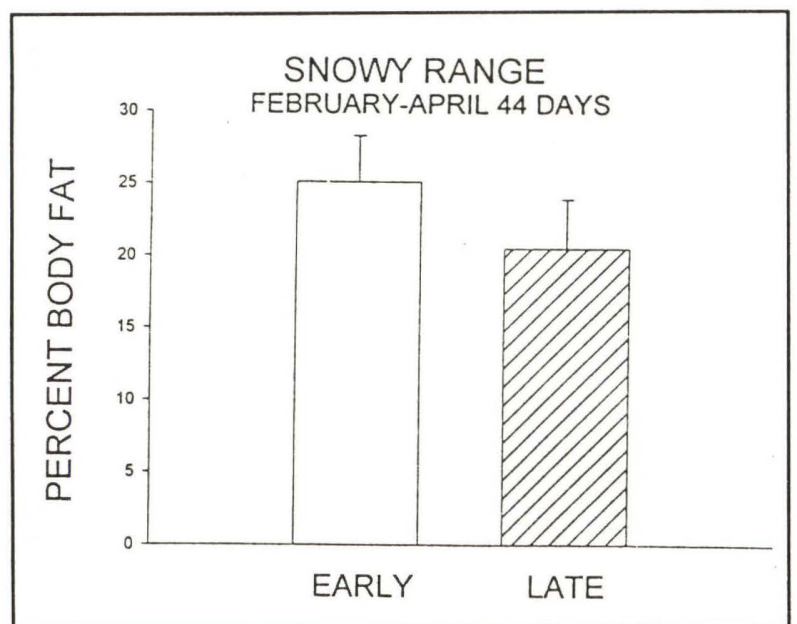

Figure 3. Percent body fat of 4 female and 1 male black bears during mid to late winter in the Snowy Range mountains, Wyoming. Vertical lines represent 2 SEM.

\section{$\downarrow \quad$ RESULTS}

Several useful trends are evident in the data despite the fact that some of the absolute values remain ambiguous and inconsistent. Average body fat content in November was $38.6 \%$ and $29 \%$ on the Uncompahgre Plateau and Middle Park bears respectively (Fig. 1 and Fig. 2). Snowy Range bears had $25.1 \%$ body fat in February (Fig. 3) which extrapolates to a fall value of about $33 \%$. Average daily body weight loss was 194, 142 and $97 \mathrm{gm} /$ day for bears in the Uncompahgre Plateau, Snowy Range and Middle Park respectively. Daily fat loss was highest for bears on the Uncompahgre Plateau (163.2 gm/day) which included the greatest number of lactating females and the largest bears while daily fat loss by the Snowy Range (95.3 $\mathrm{gm} /$ day) and Middle Park ( $85.3 \mathrm{gm} /$ day) bears was very similar (Fig. 4).

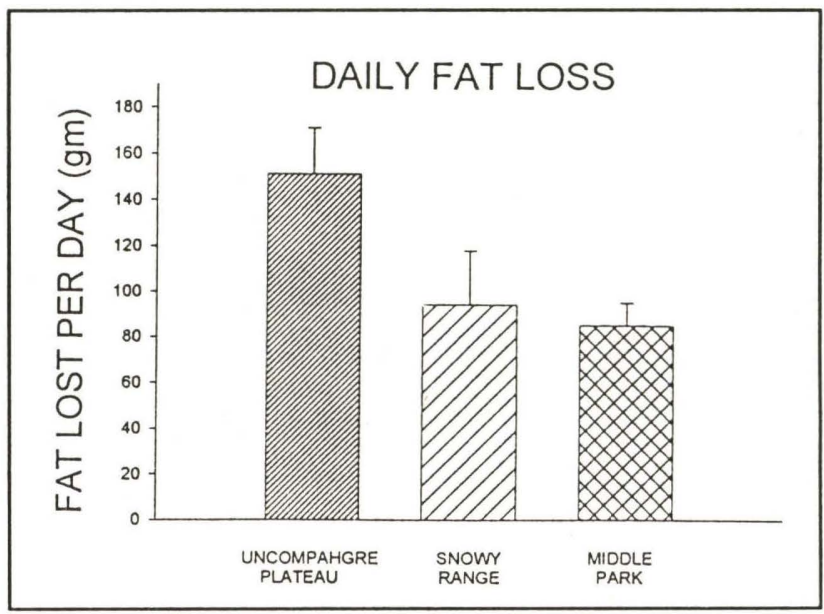

Figure 4. Daily fat loss (gm/day) by black bears from the Uncompahgre Plateau, Middle Park and Snowy Range mountains. Vertical lines represent 2 SEM.

\section{$\downarrow \quad$ DISCUSSION}

The use of BIA as a field method for determining body fat has positive attributes. It is light, easy to operate, and is inexpensive. Many laboratory and clinical studies have been conducted to validate the reliability of this instrument by comparing values against other accepted methods such as total body potassium, anthropometric methods and isotope dilution to determine total body fat for patients under clinical care (Roubenoff, 1996; Suzuki et al, 1996 Brummer et al., 1992; Young and Sinha, 1992). However, there are an equal number of studies that report BIA to be unsatisfactory by either under or over estimating body fat stores (Wagner et al. 1997; Oppliger et al., 1992; Fulco et al., 1992). Farley and Robbins (1994) found a close correlation between estimated fat derived from tritiated water dilution for black bears. However, their study was conducted under laboratory conditions without the many variables faced by field studies such as irregular terrain and animals with minor injuries.

Body fat estimated from Farley and Robbins (1994) study of captive bears was about $31 \%$ of their body mass during the fall. This value is below the only other reported body fat content of bears (45\%) determined by Lundberg et al (1976), 
also on captive bears. These studies represent the basis upon which biologists have estimated energy use, time of emergence, cub production and spring mortality by bears exposed to varying field conditions. Until now, there has not been a study to provide direct estimates of fat content of free ranging black bears.

The data from our study appear useful in terms of trends and patterns. For example, the average of all bears sampled in the fall was close to that extrapolated from Farley \& Robbins (1994) with a fat content of $34.1 \%$ which decreased to $22.2 \%$ in the early spring. Absolute fat content (\% fat $x$ body mass) was reduced an average of $48 \%$ for all bears tested. These figures are lower than those previously reported in tritiated water experiments on captive bears, but show a proportionately similar loss of fat during hibernation (Lundberg, 1976). The Uncompahgre Plateau, during the year sampled, had abundant food availability as acorn, (Quercus gambelii) and pinion (Pinus edulis) nuts and can be considered rich in energy compared to the other study areas. The high fall fat values of bears from the Uncompahgre Plateau (39\%) reflect this difference in food quality compared to bears from the other two areas (average fall body fat of $31 \%$ ). Additionally, the daily fat loss of $163 \mathrm{gm} /$ day for the Uncompahgre Plateau population is about $45 \%$ greater than the average of the other two groups of bears. The higher fat utilization may be a function of the greater body mass of these bears but it may also be a result of the additional demands for energy and water placed on the lactating females by nursing cubs. Values from this study are close to those predicted by Maxwell et al. (1998) who used metabolic models of black bears under conditions of open exposed dens (150 gm fat/day) and partially closed dens (138 gm fat/day).

However, several inconsistencies in the data collected from these field populations cause reason for concern. It is suspected that in several instances body fat was overestimated by BIA. Three bears in the Middle Park study area and one in each

Table 1. Rates of body weight and fat loss. Percent weight loss accounted for by fat loss. Total fat loss over a standardized 130 day winter. Values represent individual bears in the Uncompahgre Plateau, Middle Park and Snowy Range mountains. Values in bold type depict questionable readings.

\begin{tabular}{|c|c|c|c|c|}
\hline & $\begin{array}{c}\text { Bear } \\
\#\end{array}$ & $\begin{array}{l}\text { Body Mass } \\
\text { Loss/Day } \\
\text { (g/Day) }\end{array}$ & $\begin{array}{c}\text { Body Fat } \\
\text { Loss/Day } \\
\text { (g/Day) }\end{array}$ & $\begin{array}{l}\text { \% Body Mass } \\
\text { Lost Accounted } \\
\text { For By Fat } \\
\text { Loss }\end{array}$ \\
\hline \multirow[t]{8}{*}{ Middle Park } & 190 & 126.7 & 67 & 53 \\
\hline & 146 & 69.2 & 61.5 & 89 \\
\hline & 562 & 105.9 & 126.9 & 119 \\
\hline & 158 & 84.1 & 54.9 & 65 \\
\hline & 179 & 153.9 & 126.1 & 82 \\
\hline & 159 & 67.6 & 63.9 & 94 \\
\hline & 101 & 76.8 & 83.3 & 108 \\
\hline & 154 & 88.6 & 99 & 111 \\
\hline MEAN(SEM) & & $96.6(10.7)$ & $85.3(10.3)$ & $90.1(8.2)$ \\
\hline \multirow[t]{6}{*}{$\begin{array}{c}\text { Uncompahgre } \\
\text { Plateau }\end{array}$} & 1550 & 189 & 88.6 & 47 \\
\hline & 1770 & 180.5 & 122.3 & 68 \\
\hline & 1900 & 248 & 176.5 & 72 \\
\hline & 1992 & 209.3 & 166.7 & 79 \\
\hline & 1160 & 191.1 & 225.7 & 118 \\
\hline & 1840 & 150 & 124.8 & 83 \\
\hline MEAN(SEM) & & $195.8(16.1)$ & $163.2(18.9)$ & $84(8.9)$ \\
\hline \multirow[t]{5}{*}{ Snowy Range } & 39 & 204.4 & 194.2 & 95 \\
\hline & 37 & 69.7 & 76.5 & 101 \\
\hline & 12 & 91.7 & 47.3 & 52 \\
\hline & 40 & 175.6 & 66.8 & 38 \\
\hline & 10 & 165.9 & 91.5 & 55 \\
\hline MEAN(SEM) & & $141.5(23)$ & $95.3(25.5)$ & $68.2(12.5)$ \\
\hline
\end{tabular}


of the other sites were shown to lose more body fat in weight than they lost in total body mass (Table 1). The overestimates in this data set suggest that BIA is not a totally reliable tool for estimating absolute body fat when used under field conditions. Despite the extreme care taken to properly use the instrumentation as directed by Farley and Robbins (1994), its sensitivities to a variety of factors such as moisture on the fur, cuts in the skin and consistent body contour, reduce its reliability as a single tool to measure body fat on free-ranging bears. Therefore, we cannot recommend that BIA be used alone for assessing body fat in wild bears under field conditions but to be used in concert with other methods such as morphometric measurements and depth of fat depots.

\section{ACKNOWLEDGMENTS}

This study was funded by an NSF grant, the University of Wyoming, NASA Pass Center and the Colorado Division of Wildlife. Special thanks are offered to Lyle Willmarth and the many volunteers who assisted in locating and handling bears during the winter.

\section{$\downarrow \quad$ Literature Cited}

Brummer, R.J.M., B.A. Bengtsson, and I. Bosaeus. 1992. Validation of body composition determination by bioelectrical impedance analysis in acromegaly. Eur. J. Clin. Nut 46:47-52.

Cattet, M. 1990. Predicting nutritional condition of black bears on the basis of morphological and physiological measurements. Can. J. Zool. 689:32-39.

Farley, S.D. and C.T. Robbins. 1994. Development of two methods to estimate body composition of bears. Can. J. Zool. 72:220-226.

Fulco, C.S., R.W. Hout, C.J. Baker-Fulco and A. Cymerman. 1992. Use of bioelectrical impedance to asses body composition changes at high altitude. J. Appl. Phys. 72:2181-2187.

Hellgren, E.C., M.R. Vaughan, and R.L. Kirkpatrick. 1989. Seasonal patterns in physiology and nutrition of black bears in Great Dismal Swamp, Virginia-North Carolina. Can. J. Zool. 67:1837-1850.

Hellgren, E.C., L.L. Rogers, and U.S. Seal. 1993. Serum chemistry and hematology oaf black bears: physiological indices of habitat quality or seasonal patterns? Mammal. 74:304-315.

Lundberg, D.A., R.A. Nelson, H.W. Wahner, and J.D. Jones. 1976. Protein metabolism in the black bear before and during hibernation. May Clin. Proc. 51:716-722.

Maxwell, R.K., J. Thorkelson, L.L. Rogers and R.B. Brander. 1998. The field energetics of winter-dormant black bear (Ursus americanus) in Northeastern Minnesota. Can J. Zool. 66:2095-2103.

Nelson, R.A. 1973. Winter sleep in the black bear; a physiological and metabolic marvel. Mayo Clin. Proc. 48:733-737.

Oppliger, R.A., D.H. Nielsen, A.C. Shetler, E.T. Crowley, and J.P. Albright. 1992. Body composition of collegiate football players: Bioelectrical impedance and skinfolds compared to hydrostatic weighing. J. Orth. Sports Phys. Therp. 15:187-192.

Roubenoff, R. 1966. Applications of bioelectrical impedance analysis for body composition to epidemiological studies. Amer. J. Clin. Nutr. Suppl. 63:459S462S.

Suzuki, J., J.D. Rouds, and D.W. Wilbor. 1996. Does multifrequency bioelectrical impedance relate to body composition. J. Surg. Res. 65:63-69.

Wagner, D.R. V.H. Heyward, P.S. Kocina, L.M. Stolarczyk, and W.L. Wilson. 1997. Predictive accuracy of BIA equations for estimating fat-free mass of black men. Med. And Sci. in Sports and Exerc. 29:969-974.

Young, R.E., and D.P. Sinha. 1992. Bioelectricalimpedance analysis as a measure of body composition in a West Indian population. Amer. J. Clin. Nutr. 55:1045-1050. 